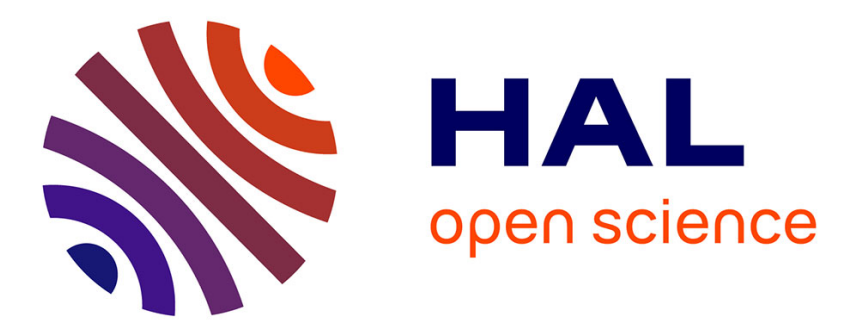

\title{
Time Management in the Work Economy of a Class. A Case Study: Integration of Cabri in Primary School Mathematics Teaching
}

Teresa Assude

\section{- To cite this version:}

Teresa Assude. Time Management in the Work Economy of a Class. A Case Study: Integration of Cabri in Primary School Mathematics Teaching . Educational Studies in Mathematics, 2005, 59 (1-3), pp.183-203. 10.1007/s10649-005-5888-0 . hal-01802900

\section{HAL Id: hal-01802900 https://hal-amu.archives-ouvertes.fr/hal-01802900}

Submitted on 31 May 2018

HAL is a multi-disciplinary open access archive for the deposit and dissemination of scientific research documents, whether they are published or not. The documents may come from teaching and research institutions in France or abroad, or from public or private research centers.
L'archive ouverte pluridisciplinaire HAL, est destinée au dépôt et à la diffusion de documents scientifiques de niveau recherche, publiés ou non, émanant des établissements d'enseignement et de recherche français ou étrangers, des laboratoires publics ou privés. 


\title{
A CASE STUDY: INTEGRATION OF CABRI IN PRIMARY SCHOOL MATHEMATICS TEACHING ${ }^{1}$
}

TERESA ASSUDE

Équipe ADEF

Université Aix-Marseille

\begin{abstract}
Time is a constraint but also a condition of operating within a didactic system. Don't we need to distinguish several kinds of times? Our study will focus on teachers' time management strategies. We will identify these strategies by taking into account two temporal dimensions - didactic time and time capital - and the rate at which the former advances relative to the latter, called the pace of an activity, a lesson or a teaching sequence. Those strategies have been identified in the specific context of the integration of the Cabri-geometry dynamic geometry software in the daily work of a French primary school.
\end{abstract}

KEY WORDS: didactic time, time capital, pace, time management, Cabri, geometry

RÉSUMÉ. Le temps est une contrainte mais aussi une condition du fonctionnement d'un système didactique. Ne faut-il pas distinguer plusieurs temps ? Comment sont-ils gérés par l'enseignant? Nous nous intéresserons au problème des stratégies de gestion temporelle mises en œuvre par l'enseignant dans une classe. L'identification de ces stratégies sera faite à partir de deux de ces temporalités - le temps didactique et le capital-temps - et des rapports entre ces deux temps, ce que nous avons appelé le rythme d'une activité, d'une séance ou d'une séquence. Ces stratégies ont été identifiées dans le contexte spécifique de l'intégration de Cabri-géomètre dans le travail au quotidien de classes de l'enseignement primaire en France.

MOTS-CLÉ : temps didactique, capital-temps, rythme, gestion du temps, Cabri, géométrie

"I have to cover the whole syllabus", "I haven't got the time to let pupils resolve the problems", "it takes too long", "I can't waste my time with this kind of activities"; such complaints are frequently heard from teachers. These complaints can even be considered as an argument against teaching based on problem solving because "it requires a lot of time and gets in the way of covering the prescribed material". The recurrent theme of "lack of time" points to time as one of the main problems in classroom management.

We will approach this problem by looking at strategies developed by teachers to manage the different kinds of time at work in a classroom. We will limit our study to some of these "times", which we will define in the theoretical part of the paper. Then we will analyze teachers' management strategies observed in a research on the integration of Cabri-geometry in a French primary school. This analysis will bring to light time management strategies, which may appear also in other situations. We postulate the generality of these strategies but do not provide evidence for it in this paper, which is focused on Cabri-geometry. 


\section{THEORETICAL FRAMEWORK AND THE PROBLEMATIQUE OF TIME IN TEACHING}

The starting point of our study is the integration of new technologies ("ICT" in the following) in mathematics teaching at the primary school, particularly the integration of Cabri, a dynamic geometry software, in the geometry practices of students. One of the issues, which led to this research, is

What are the conditions and constraints that make possible the integration of

Cabri in teaching without creating a clash between tradition (i.e., what is usually done) and innovation?

One of the conditions, developed in a previous paper (Assude and Gélis 2002), is to find the "right distance" between the old and the new as far as the functioning principles of the class, as well as the types of tasks and available techniques, are concerned. In the present paper, we want to stress other conditions, related to different kinds of time and teachers' management strategies in relation to these kinds of time.

The question of time management in integrating ICT is a key issue, which, so far, has not received sufficient attention in research. There are several reasons why this issue should be addressed. One of them has to do with the subject matter to be taught: how to divide it up over a period of time when using the ICT? This is not explained in syllabuses, and can create a difficulty for teachers who start using them because they don't know for sure what to do and how to do it. Another reason why it can be hard on teachers concerns the time devoted to becoming familiar with the software and to learn how to operate it: time has to be spent (sometimes too much) to familiarize students with the software before any time can be gained in the learning process. How to shorten the familiarization process yet give students sufficient control over the software (so that they don't feel awkward with it) to make its use more "economical"? Time is both a constraint and a condition in implementing this new way of doing mathematics, as it is in every case, which makes it a relevant variable when studying the functioning of didactic systems. As Lemke (2000) says: "Every human action, all human activity takes place on one or more characteristic timescales". What timescales do we need to identify to answer our questions?

The existence of different kinds of time in a classroom has been noticed and studied by several researchers. Chevallard \& Mercier (1987) and Leutenegger (2000) showed how the didactic time is important in textualising knowledge and regulating the didactic contract. Brousseau \& Centeno (1991), and Matheron (2001) studied the importance of didactic memory to remember past events when pupils are learning something new. Following Varela's works (1999), Arzarello et al. (2002) distinguished two times: "physical time" or clock time, and "inner time", which emphasizes actors' time, especially pupils' learning time. Pupils' learning time was also studied by means of didactic biographies by Mercier (1995), or other ways such as the "fractions diary" (Sensevy 1996), or a multiple device that construes remembering as a process encompassing memory, attention and waiting (Assude \& Paquelier 2004). What kinds of time are we speaking about? Physical time, didactic time, 
teaching time and learning time. These kinds of time can be displayed on a smaller scale and then we could speak about kinds of time such as, for example, the time of a mathematical narration, or the time of a mathematical discussion (Arzarello et al., 2002).

In this paper, since we are interested in teachers' time saving strategies, we will concentrate on the following concepts: didactic time, time capital, pace, which we are now going to define and explain.

Didactic time is defined par Chevallard and Mercier (1987) as related to scheduling the teaching of some knowledge. Didactic time is produced by the textualization of knowledge, which results from the process of didactic transposition, i.e. the process of transformation of a body of knowledge into a knowledge that can be taught (Chevallard, 1985). Didactic time is linear (the objects of knowledge follow one another in linear order) and sequential (knowledge is divided in syllabus items, which are then arranged in tasks, lessons, courses of lessons). Didactic time is used as a gauge of the advancement of knowledge, and, in this sense, it is a framework, which regulates the activity of the teacher. In France, syllabuses prescribe the portion of knowledge to be taught but the teacher is relatively free to divide it in lessons and sequences of lessons according to his pupils' progress. So our question is: How does the teacher manage this didactic time when the divisions have not been previously made at all, or not made to fit with the use of ICT in teaching?

A second temporal element is the time capital, i.e. the "objective" time counted down by the clock and available for the classroom work: the year, the month, the day, the hour, and the minute. Such time cannot be compressed but represents a capital, i.e. the value attributed to each time interval depends on what can be done within it. Management of this time capital by the teacher takes into account the estimated temporal cost of each activity and the global time of all activities put together. For example, a teacher may deem a particular problem solving activity a waste of time, since the temporal cost of implementing it is very high compared to all situations put together. Another activity may be seen as time saving, since it does not require spending too much of the time capital. As Pronovost (1996) says: "most anthropologists, who had studied this issue, emphasized that social time is also structured according to meaningful activities of which it is made. There is a meaningful relation between symbolically constituted temporal periods and the content of activities". ${ }^{2}$

By dividing his time capital into activities, syntheses, assessments, the teacher organizes the work in the classroom. A smaller time scale can be taken into account: thus activity time is time capital devoted to classroom activities, synthesis time is time capital devoted to whole class syntheses of previous work, and assessment time is time capital devoted to tests or other kinds of examinations.

We can go further in dividing the time capital. For example, activity time can be seen as a more general category including times such as tool time (time needed for becoming familiar with and learning how to use a tool), time for individual work, time for working in small groups, time for whole class discussion, etc. Those times are interconnected and partly inclusive. For example, in a situation where the pupil is required to use Cabri, the tool time of the software is included in the pupil's 
working time; but, in some situations, the pupil does not use the tool but only describes what the teacher had been doing with the software. These activity times may also be explained in more specific terms with respect to given mathematical content and/or type of activity. As we will see in section 4, the time of a figure construction activity is not the same as the time spent on analyzing a previously constructed figure.

How does the teacher manage these different times in the classroom? We propose that the teacher views the time $\mathrm{he}^{3}$ has available indeed as a certain capital, which can be used (invested) in different ways. He makes decisions based on his assessment of the costs of relations such as the relation between tool time and didactic time; the relation between activity time and didactic time; the relation between tool time and activity time, etc., in view of saving as much time capital as possible, whilst promoting didactic time and pupils' learning time.

Investment in time capital does not necessarily yield a gain in didactic time. We can suppose it does, or wish for it, but does it really happen?

We will call the pace of a course or a part of it, the rate at which didactic time advances relative to the time capital allotted to it. The pace can be slow, fast or moderate. Diagrams 1-3 illustrate what we mean by these different possibilities.

Diagram 1 represents a fast-paced course: didactic time makes rapid progress compared to the time capital that is being spent. We may expect that, in this situation, pupils will not be able to follow the pace, and the teacher will have to return to the subject later in the course.

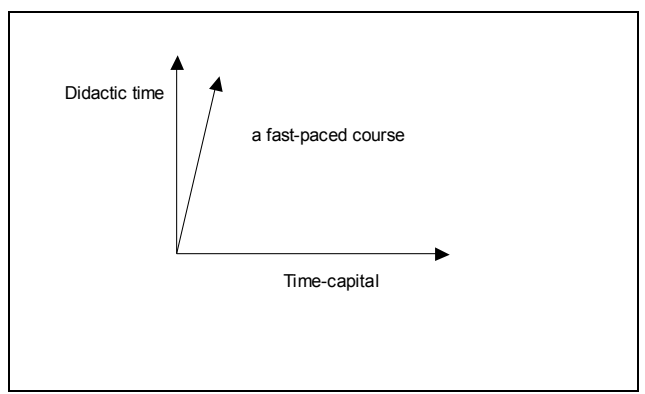

Diagram 1: A fast-paced course

Diagram 2 represents a slow-paced course: knowledge is not moving very much forward while a large amount of time capital is being spent. We can expect difficulties with covering the material; the teacher must monitor his actions if progress in didactic time is to be achieved. 


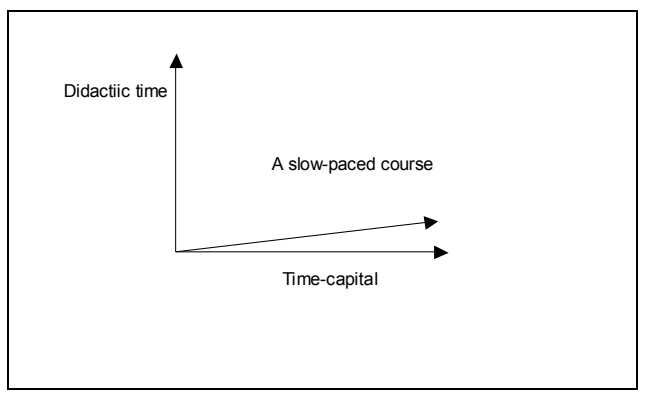

Diagram 2: A slow-paced course

Diagram 3 illustrates a moderate-paced course, where a reasonable amount of time capital is spent to achieve progress in the didactic time.

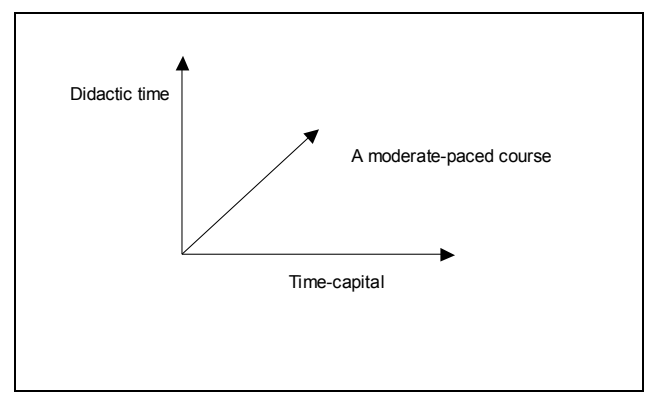

Diagram 3: A moderate-paced course

In a moderate-paced course, the teacher can still try to save more time capital, by making use of time saving strategies. We will give some examples of these strategies later on.

Based of these theoretical elements, our research questions are the following:

- How does the teacher manage his didactic time?

- How is the pace of activities taken into account, if it is taken into account at all?

- What time management strategies should the teacher adopt to use his time capital in the most efficient way?

Before answering these questions, we briefly outline the context and the methodology of our research in the next section.

\section{THE CONTEXT AND METHODOLOGY OF RESEARCH ${ }^{4}$}

Research into the integration of Cabri software was carried out in two $\mathrm{CM} 2^{5}$ classes during the school years 2000/2001 and 2001/2002. Our team of two researchers and two teachers shared their tasks as follows: the teachers were responsible for choosing and implementing classroom situations, the 
researchers served as resource providers through the production of a "task box" ${ }^{6}$ and they observed the classes; researchers and teachers analyzed the data together.

The body of data was constructed on the basis of teachers' lesson preparation notes, pupils' exercise books, classroom observation (video- and audio-recordings and researchers' field notes). The analyses that follow concern all geometry-related activities, and more particularly the subject of quadrilaterals. This subject was chosen because it was included in the curriculum for this grade level.

We will use the comparison between the different years to highlight the different types of time in presence, the relationships between these times, and what this tells us about teachers' time management strategies. The comparison between the outlines of topics and activities covered in 1999/2000 (before the integration of Cabri) and in 2000/2001 (first year of integration) will allow us to analyze the changes brought about by the presence of the software in the production of didactic time. The comparison of such outlines for the years 2000/2001 and 2001/2002 (second year of integration), will allow us to identify different strategies adopted by the teacher in the aim of saving time when working with Cabri.

\section{ACHIEVING CONTROL OVER DIDACTIC TIME}

The production and management of didactic time are a challenge for a teacher, no matter whether he is a beginner or an expert, whenever he has a new subject to teach or a new technology to integrate. The teacher often does not know what to do, what is essential to do, or how to do it.

We will now compare the two teachers' management of didactic time, before the integration of Cabri and in the first year of this integration (see Table 1). We will be looking for essential differences.

Table 1. Comparing didactic time without and with ICT

\begin{tabular}{|c|c|}
\hline Year 1999/2000 (without software) & Year 2000/2001 (with software) \\
\hline $\begin{array}{l}\text { 1) Reproduction of plane figures (5 hours) } \\
\text { - reproduction of complex figures } \\
\text { - use of geometrical instruments (ruler, } \\
\text { compass, set-square, etc) } \\
\text { - use of precise geometrical } \\
\text { language (line segment, ray, } \\
\text { straight line, arc of a circle, } \\
\text { centre, radius, right-angle, etc) } \\
\text { - recognition of certain figures } \\
\text { - reproduction of polygons } \\
\text { - classification of different polygons } \\
\text { - identification of geometrical properties } \\
\text { of figures } \\
\text { 2) Construction of geometrical figures using a } \\
\text { construction programme }{ }^{7} \text { (5 hours) }\end{array}$ & $\begin{array}{l}\text { 1) Reproduction of plane figures (without } \\
\text { software) (5 hours) } \\
\text { - reproduction of complex figures } \\
\text { - use of geometrical instruments } \\
\text { (ruler, compass, set-square, etc) } \\
\text { - use of precise geometrical } \\
\text { language (line segment, ray, } \\
\text { straight line, arc of a circle, } \\
\text { center, radius, right-angle, etc) } \\
\text { - recognition of certain figures } \\
\text { - reproduction of polygons } \\
\text { - classification of different polygons } \\
\text { - identification of geometrical properties of } \\
\text { figures } \\
\text { 2) Familiarization with Cabri ( } 3 \text { hours) }\end{array}$ \\
\hline
\end{tabular}




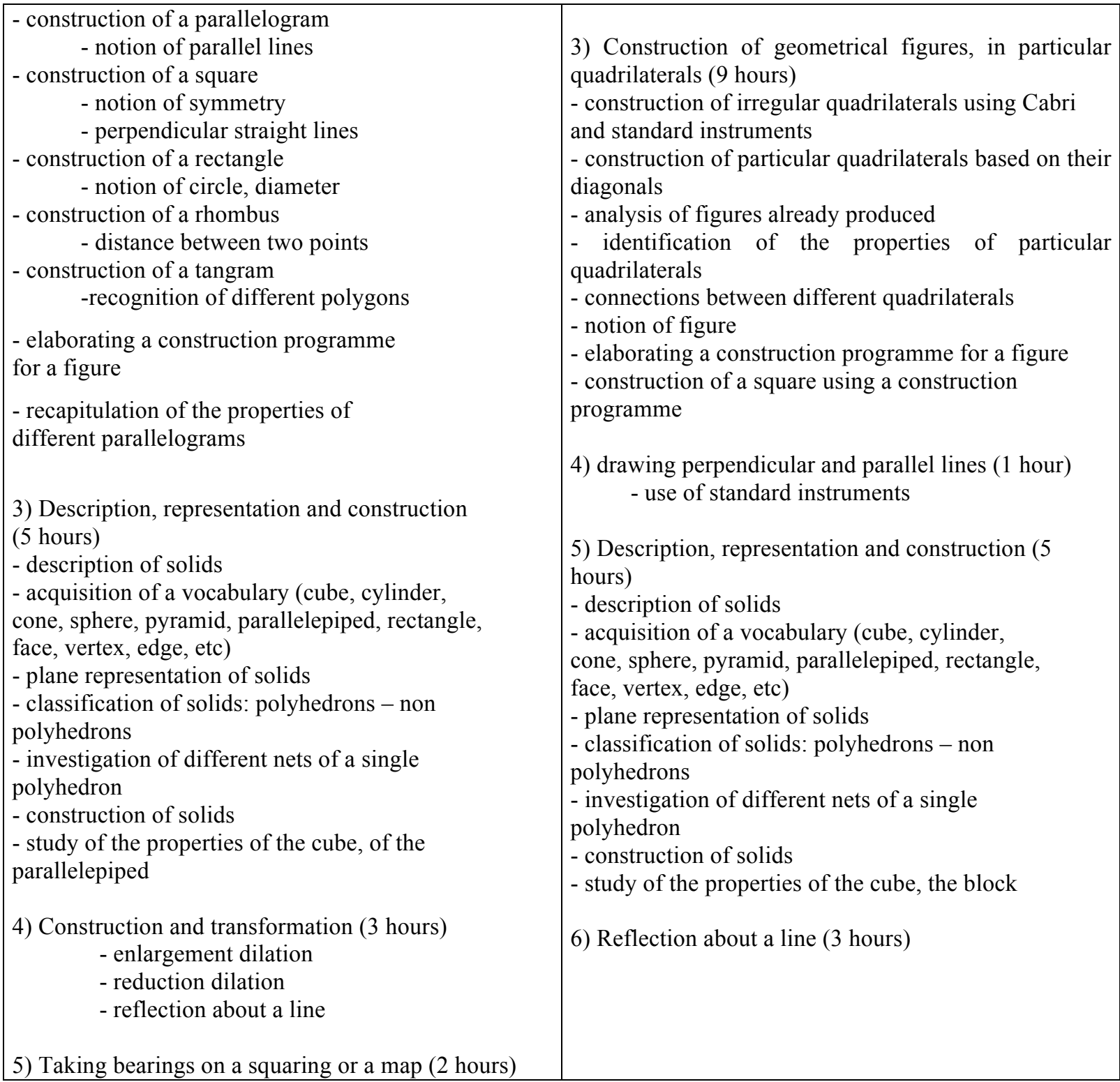

The outline of the geometry course for the year 2000/2001, compared to that of 1999/2000, preserved the reproduction of plane figures (item number 1), on the description and reproduction of solids (item 3), and reflection about a line. Some differences can be observed: familiarization with the software was added in 2000/2001, as expected; and there was a change in the construction activities. In the year 1999/2000, pupils had to construct particular quadrilaterals using a construction programme and, during these constructions, they encountered drawing requirements such as constructing parallel or perpendicular lines. Thus the concepts of parallelism and perpendicularity of two straight lines appeared to pupils as answers to construction problems. In 2000/2001, pupils using Cabri primitives did not encounter these concepts as construction tools, and therefore their teachers added a unit on parallelism and perpendicularity, where such lines were drawn using standard physical geometric instruments. The teachers viewed this addition as problematic. In their ordinary lessons, they would try to find situations, in which concepts would appear as tools for solving encountered 
problems. This unit was not justified this way, and therefore adding it appeared to the teachers as a breach of their standards of practice. However, in the first year of integration of the software they felt they had no choice but to add this isolated unit because it was explicitly part of the curriculum.

Another difference is that, in the year 2000/2001, the teachers did not have the time to include the units on dilation or location in the plane. It is worth noting that 13 hours were spent on items 2,3 and 4 of the 2000/2001 outline, while 5 hours were spent in 1999/2000 on the corresponding item 2. Time capital cannot be stretched, and if a decision is made to use some of it on integrating Cabri, one should be aware that certain items on the outline would have to be dropped.

The integration of Cabri in the two CM2 classes did not cause any major changes with regard to the broad types of tasks: construction, description and property identification. However, there were local changes in the tasks and the types of techniques used (for more details see Assude \& Gélis 2002). For example, constructing a particular quadrilateral from diagonals is a new task for pupils. This task was first assigned in the pencil and paper environment, and then with Cabri, and it involved working on the properties of diagonals of particular quadrilaterals. It became an essential point of the entire general unit on quadrilaterals, since it allowed work on the concept of property as a construction tool and as a means of characterizing a particular quadrilateral.

One comment can be made regarding the old/new dialectic: integration does not mean a complete revolution with respect to former practices. While some practices remain, for example preparing a construction programme or constructing a square by means of a construction programme, new ones appear, for example constructing quadrilaterals starting from their diagonals. One factor of integration appears to us to be the "right distance" between the old and the new in regard to the proposed types of tasks.

This condition of integration - even though essential from our point of view- was not identified as such by the teachers, who repeatedly mentioned the discomfort of working in a hurry, without knowing what was coming next, the taking of risks, the radical change in how they planned and conducted their lessons. Yet a degree of consistency was built up by interconnecting the old and the new in terms of principles, tasks and techniques. So why did the teachers experience discomfort?

To incorporate the work with Cabri into their geometry course outlines, the teachers adapted the outline of the previous year's course. But this adaptation did not necessarily allow the teachers, in the first year of integration of Cabri, to have a global vision of the new didactic time. It was necessary for them to accept this temporal instability in order to step into this "adventure", in which they took many risks (as they themselves admitted). The shift from "day-to-day" management to a more global control over didactic time appears to us to be another essential condition of integration. Control over didactic time implies tracing out a temporal division of knowledge (an order) that is linear and fits logically into the overall work of the class. Such control gives teachers a general view of how knowledge unfolds over time, even though it is possible to change things afterwards, and makes it possible to anticipate pupils' difficulties during this progress. Didactic time appears here as a 
framework and as a means of regulating the teacher's activity; this role of didactic time was overlooked in the first year of integration.

In comparing the first and second years of our research, we noticed an increase in teachers' control over didactic time. During the year 2001/2002 (third year of our research project), teachers started from the previous year's outline, changing some items that appeared problematic, and trying to provide for time saving actions (this point is taken up in more detail below). For example, systematic revision work was carried out on the circle and on the diagonals of a polygon prior to Cabri lessons, because a lot of time was wasted in the previous year on making these revisions during Cabri lessons. In addition, this second year proved to be an easier experience, since teachers were could anticipate what pupils would be doing and therefore they were able to manage their time more economically: they were saying, "we know where we're going”, “we don't need to rush", "things can be planned in advance". Without the necessary landmarks, as in the first year of integration, teachers did not know when to speed up and when to slow down. The difference between the first and the second year could be explained, largely, by the teachers' greater command of both the software and the didactic time in the second year. It made it possible for them to anticipate the time things would take and how they would be inter-related in the mixed paper and pencil and ITC environment, and thus to establish a tentative temporal order, which, even if not kept, was open to absorb any unexpected irregularities or gaps.

We shall now see how, when teachers have control over didactic time, they can manage various times in a different way in order to save time in their work with Cabri. To do this, we will analyze the unit on quadrilaterals.

\section{TIME ECONOMY AND THE PACE OF SITUATIONS}

In each of the two years of integration of Cabri, the unit on quadrilaterals was organized in three stages each of which occupied two to three one-hour classroom periods:

- The first stage focused on the construction of quadrilaterals, with a paper and pencil phase and a Cabri phase. In the former pupils had to construct quadrilaterals starting from diagonals, in the latter - they had to construct quadrilaterals using the software. In both phases, pupils could construct particular quadrilaterals of their own choice.

- The second stage was devoted to analyzing figures. The analysis of paper and pencil figures aimed at the identification of different quadrilaterals and their properties (for example, identification of a square and its properties). The analysis of Cabri figures was meant to draw students' attention to the distinction between a drawing and a figure ${ }^{8}$ and to the relationships between different quadrilaterals (for example, the fact that a square is a particular type of rectangle ${ }^{9}$ ).

- $\quad$ The third stage focused on the construction of quadrilaterals with paper and pencil and with Cabri, in particular the construction of a square starting from the diagonals, or starting from a 
side, using a construction programme written on the basis of the "construction replay" feature ${ }^{10}$ of Cabri. This third stage closed with an assessment phase: pupils were asked to draw a square following a construction programme.

These three stages in the unit on quadrilaterals were determined by variously paced activities. A construction activity was much slower than an activity in which previously constructed figures were analyzed, and a very open-ended construction situation such as those in the first stage was much slower than a construction activity with standard instruments following a construction programme. When we say that the pace is slower, we mean that the relation between the pupils' working time and didactic time is not economical relative to time capital, because didactic time hardly moves forward: pupils must have sufficient command of the software in order to do the constructions, which is not necessarily the case for analysis; moreover, since the situation can be very open-ended, collective time is also more important.

Each activity proceeds, therefore, at a different pace, and becoming aware of that allowed teachers to make decisions and choices as to the types of activities. Pace is therefore one factor of selection of activities amongst others, such as the knowledge to be taught. For example, during the first year of our research and the first lesson of the first stage, pupils were working individually, with half of the class constructing quadrilaterals using Cabri, and the other half constructing them in paper and pencil environment starting from specific diagonals: the situation was so open that most pupils were lost. A decision regarding what to do next was necessary: the situation was closed down by means of a pencil and paper activity requiring the identification of the properties of diagonals based on an analysis of figures, and, in the second stage, a faster paced activity was chosen, namely the analysis of figures previously constructed with Cabri.

However, the teachers thought that the pace obtained in the first year was globally convenient and they reintroduced it in the second year with respect to the succession of construction, analysis and construction activities, since it allowed pupils to master the software and, at the same time, to advance the didactic time in terms of new mathematical content. The pacing of the sequence of activities is all the more noticeable as there is a main axis of focus for the 3 stages. This axis is the notion of properties of the quadrilaterals, since the properties are used both to characterize and construct particular quadrilaterals.

Besides this notion of pace of a sequence of activities, every activity also has its own pace, which can be a factor in choosing it, for the teachers. In the first year of our research, the teachers dared not intervene orally in the whole classroom except when giving their final synthesis of each activity. They had noticed that in some cases an intermediate synthesis was a way to boost the work of individuals who were lagging behind; however, they wouldn't risk doing this in the first year, thinking that they oughtn't intervene in the pupil's working time. In the second year, the pace of some activities was changed. We could observe several strategies. 
One of the strategies was to cut down on secondary activities and go directly to the heart of the matter. For example, the first lesson required the production of many different quadrilaterals, which were then classified. At that time classification was not an essential element and was very costly in time capital, since the pupils had not constructed very varied quadrilaterals and it would have been necessary for the teachers to start working again, making it clear at this time what they wished to obtain. In the second year, classification was no longer taken up as a target objective in the activity.

Another strategy was to familiarize pupils with mathematical objects that appeared problematic for students in the first year, prior to the lessons with Cabri. In the first year, some pupils no longer knew what a diagonal was and the teachers spent much of the available time capital on necessary revision work thus somewhat disrupting the planned pace of the activity. In the second year, they chose to revise the concept of diagonal earlier in the course, when dealing with the reproduction of plane figures, particularly polygons.

Another strategy was to change pupils' relationship to an object of knowledge in view of its prospective use in the Cabri environment. For example, pupils' relationship to the compass in the first year did not include the use of the instrument to transfer lengths. But when teachers wanted pupils to use the "compass" primitive in Cabri, they had to revise the use of the compass and the notion of circle. In the second year, pupils were asked to reproduce figures including circles using the compass to transfer lengths, which made it possible to save time.

Yet another strategy, introduced in the second year, involved giving intermediate syntheses; in those brief syntheses one or two pupils would be asked to show how far their work had progressed. The teachers would make sure beforehand that these pupils' input would advance the work of others.

Finally, we observed a strategy consisting in teachers' making "small" authoritative contributions. In the first year, they dared not make comments during individual work done by pupils; however, in the second year they believed that certain contributions could help save time. For example, some pupils were unable, in Cabri, to draw a circle passing through a point, because they did not know that it is necessary to specify to the software that the circle should be "passing through this point". In the first year, teachers discovered pupils' usage patterns, such as the one just mentioned. Without experience in using technology with pupils, teachers would not be able to anticipate those patterns. In the second year, the teachers, already aware of this difficulty, showed pupils what needs to be done. This input of information was beneficial to some pupils, who, without it, could not understand why their circle was not passing through the required point.

Those different strategies allowed to change the pace of some activities and to save time capital. Let us see now other time saving strategies.

\section{TIME ECONOMY AND THE INDIVIDUAL/COLLECTIVE RELATION}

In a discussion with the teachers at the end of the first year, one of the teachers said, with reference to the unit on quadrilaterals: "we spent too much time and the pupils did not have enough time". This 
means that too much time capital was spent, while didactic time did not advance and the "tool time" for getting familiar with the software was insufficient. She thought that pupils had not had enough usage time overall. How can didactic time be made to advance more rapidly while increasing the tool time? Several strategies were implemented during the second year of experimentation. Here we give two examples, one in this section and the other in the next. The first example is concerned with a strategy that makes use of the relation between the individual and the collective activity.

One of the sessions on quadrilaterals was based on a series of activities based on questions about preconstructed Cabri figures. Figure 1 shows an example of such activity. In this activity, a Cabri file opened on a square that had to be put out of shape. The drawings obtained from this Cabri figure were all rhombuses, due to the geometrical properties governing the construction of the initial square. The objectives of the proposed task were both instrumental and mathematical. In instrumental terms, it focused on the distinction between figure and drawing and on the invariance of the properties used in the construction of the figure under the change of its shape. In mathematical terms, this task provided an opportunity to revise the properties of different quadrilaterals (showing that a quadrilateral is a rhombus by measuring the lengths of its sides with Cabri) and to work on inclusions between classes of particular quadrilaterals (every square is a rhombus, but not all rhombuses are squares). The other activities were similar and concerned other pairings of particular quadrilaterals (such as rectangles and squares, or parallelograms and rectangles).

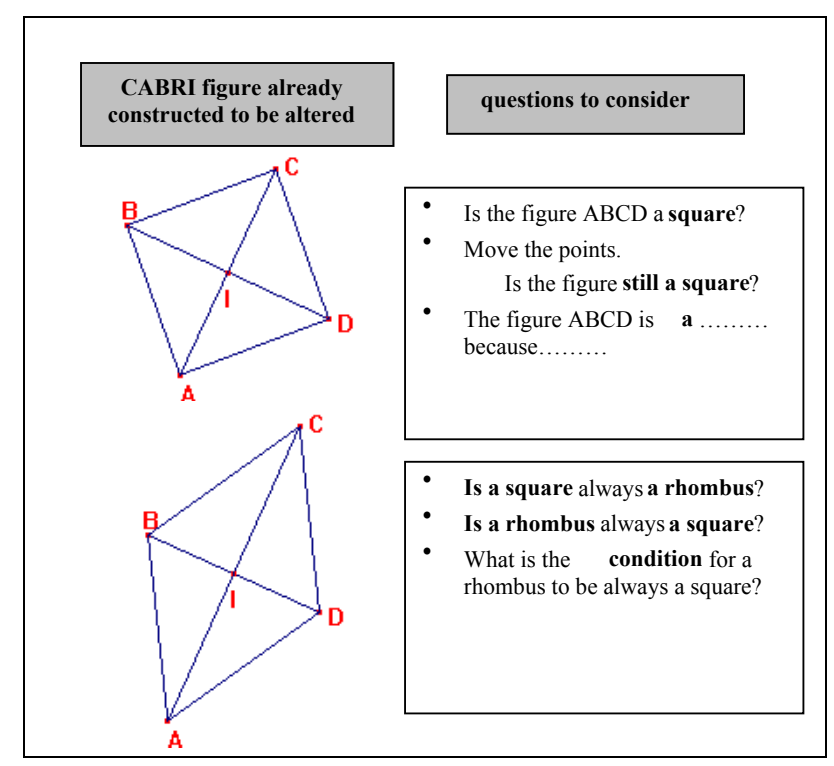

Figure 1: Example of type of task proposed

There were five exercises of the same type, where the pairings of quadrilaterals changed. During the year 2000/2001, all pupils had to complete all five exercises and the teachers did not have enough time to make a synthesis at the end of the class. They were compelled to allow the pupils to finish the exercises during another class, where there was also a synthesis and institutionalization 
phase for the mathematical and instrumental knowledge involved in these tasks. In this case, much time capital was spent whereas pupils did not have much tool time and no progress was made in didactic time.

In the second year of the research, a different choice was made concerning the same activities. Each pair of pupils was presented with only three of the activities, but the whole class was presented with all of them. Thus, the teachers added tool time and, in the phase of synthesis, all pupils became acquainted with all of the activities, either first hand or through the reports of other pupils. The teachers achieved a gain in time capital and the attention time of pupils did not flag, as in the first year, because the pupils had to give an account of their activity, and they realized they had the same drawing but not the same figure. For example, two pairs started with a square but those squares had not been constructed in the same way: one was constructed as a rectangle, the other as a rhombus. Here, too, there is a gain in time capital (instead of two class periods, one and a half was enough), in tool time and in pupils' working time: pupils paid more attention to the mathematical content of the activity, partly because their curiosity was aroused by noticing that they had the same drawing but not the same figure.

\section{TIME ECONOMY AND MATERIAL OR SYMBOLIC MEANS}

We shall presently show how, in relation to the synthesis made during these activities, the teachers adopted a strategy that enabled them to save time by using a poster that freezes the dynamic properties of Cabri.

As mentioned, in the second year, individual pupils got acquainted with three activities only, but collectively they saw all of them. The pupils worked in pairs, and afterwards a collective synthesis was organized as follows. Each pair presented their work using the software, and after the presentation and discussion, the teacher displayed the information provided by each pair in a poster (Figure 2).

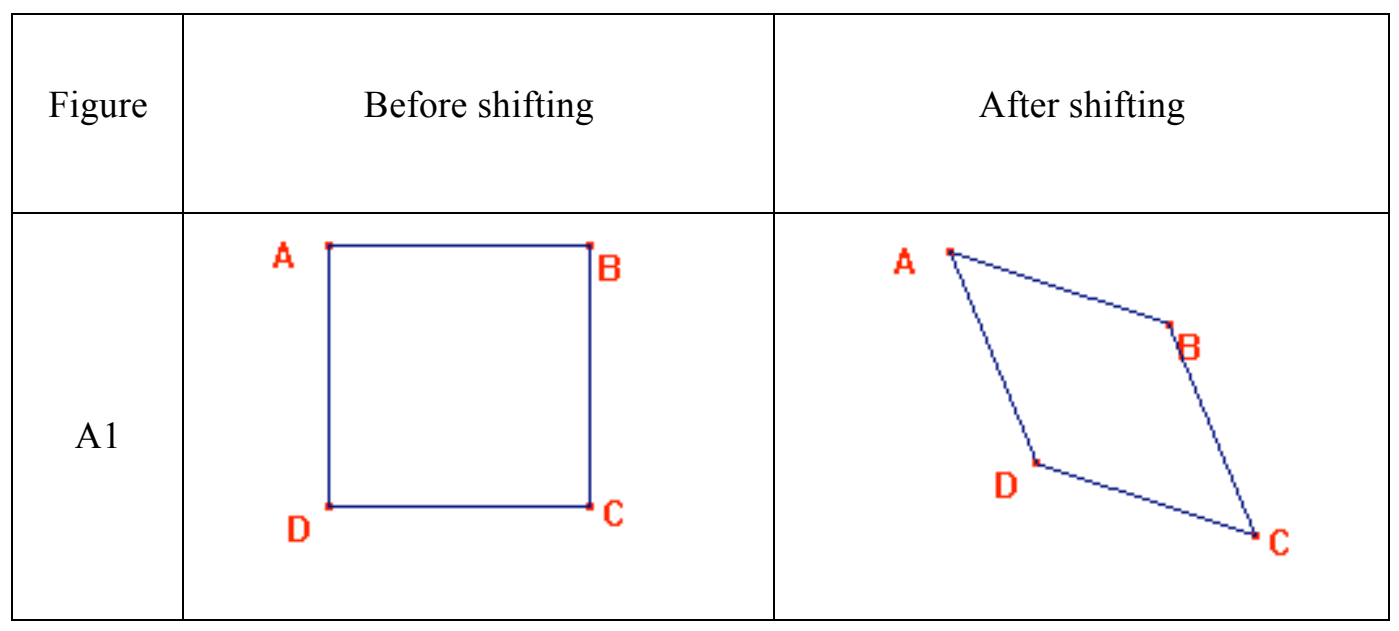




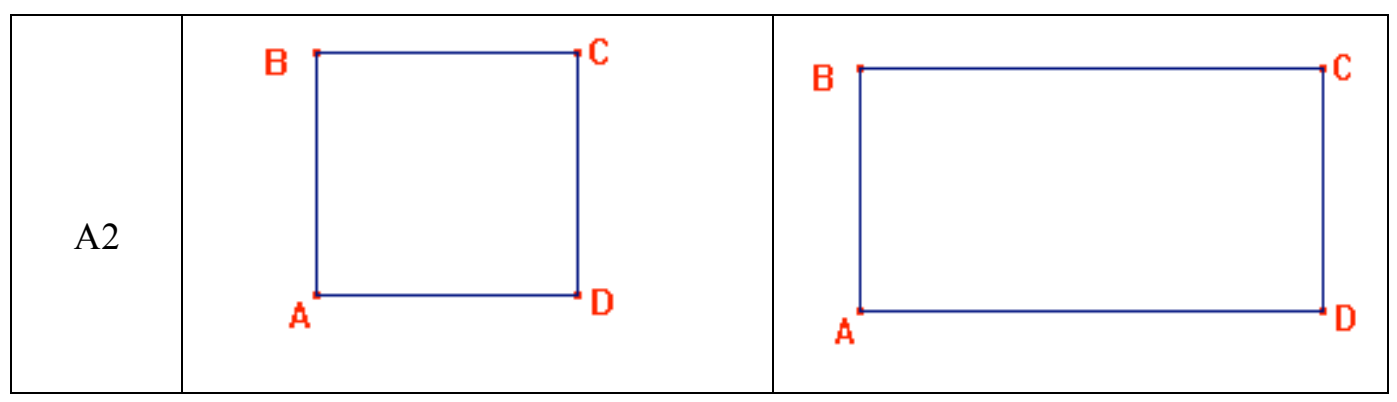

Figure 2: Information processing poster

By freezing the dynamic properties, the poster condenses the essential information of the activity. Thus, each pair presented the cases they had worked on or placed them in the context of the cases already presented. The use of this poster made it possible to leave a trace of the work of each pair and the teachers used it to institutionalize the mathematical knowledge concerned: in particular, the relations between different quadrilaterals and their properties, as well as the difference between drawing and figure. In addition, this poster allowed pupils to understand the purpose of the situations, as some affirmed in the synthesis afterwards when the teacher gave a recapitulation of the session. For example, one pupil said: "The square has all the properties of the rhombus, but it also has other properties", while another pupil said: "Had we constructed a square, it would remain a square, it would have right angles".

This poster is a means of processing information that saves time, since pupils represent and then visualize the different activities, instead of talking about all of the activities without representing them. This way of representing activities is also a means of freezing the dynamic properties of Cabri. The dialectic between static representation and the dynamic properties of Cabri figures provides pupils with a better understanding of cases they did not study compared to cases they studied themselves, and of the purpose of the situation. Taking a snapshot of a Cabri activity also served as a means of classroom management by the teacher, since it enabled her to process information from pupils' work in relation to her objectives. One of the management difficulties expressed by the teachers was that of getting information from the pupils' work which they wished to later use in the synthesis: "everything happens very quickly", “there isn't enough time to see what they are doing and suddenly they are on to something else". By freezing the dynamic properties of Cabri, by leaving a static trace of an activity in a poster, the teachers partly resolved the problem of splintered observations and information regarding pupils' individual work, since they channeled the type of information that the pupils would be presenting during the synthesis. The information that interested the teachers was primarily concerned with the mathematical and instrumental knowledge that had to be taught.

The poster shows the purpose of the activity, and the institutionalized content that pupils are supposed to know. 


\section{CONCLUSION}

Teachers' feelings about time expressed in the introduction to this paper point to the difficulties of time management in the classroom. What can be done to manage time capital while taking into account the different times and bearing in mind that didactic time must move forward ("the syllabus has to be covered")? In our research the comparison between work carried out before the integration of Cabri and the first year of integration, and subsequently the comparison between the first and second year of integration, shows several conditions of integration linked to the problem of time.

One of the conditions of integration is the teacher's command of the didactic time, which allows the teacher to have a global view of how the teaching of certain content is progressing, and to have an idea of what has to come after an activity. This condition allows teachers to know where they are and where they are going. This condition cannot necessarily be satisfied in the first year of integration of new technologies. We think that even experienced teachers (the teachers participating in our research had each been teaching for more than 15 years) are not necessarily ready to face time management difficulties when the way of working with the class changes and when ready-made outlines are not available. Indeed, we have to work hard to create and to distribute scenarios of Cabri integration in primary school to assist teachers who are starting on this "adventurous road". But it is probable that teachers who invest themselves more readily in this process of integration are those who accept a degree of temporal instability due to an initial lack of control over didactic time. Didactic time has an important functional role in classroom management, because it allows the teacher to anticipate pupils' difficulties and to work on the pacing of particular situations or their sequences. Several strategies are used by teachers to achieve saving time of working with Cabri (the software has to be mastered and has to provide gains in terms of the quality of pupils' learning without spending much time capital).

Another condition of integration is therefore that of saving as much time capital as possible by manipulating the relationships between the different times using multiple strategies. The strategies observed in our work were as follows:

- fine-tuning of the individual/collective relationship;

- using material or symbolic means such as posters that make it possible to condense pupils' work information by freezing the dynamic properties of Cabri;

- knowing when to go to the heart of the matter, which is not unconnected with control over didactic time;

- changing the order in which material is taught, either to revise aspects where difficulties persist (for example: diagonals) or to change the relationship to an object (example: use of the compass to transfer lengths);

- making intermediate syntheses or "small" authoritative contributions. 
Such strategies allowed the teachers to save their time capital in working with Cabri and, as a result, this software could be integrated in the day-to-day work of the class.

As we said in our introduction, we think that time management strategies observed in our research are not specific to this particular situation. They can be found in other situations. Identifying generic strategies of time management is not the purpose of this paper but through this particular example we can already show that time is a key point in classroom management. We believe research in mathematics education should to take it up as a worthwhile issue.

\section{NOTES}

\footnotetext{
${ }^{1}$ I want to thank Anna Sierpinska for her help in improving the english of this paper.

${ }^{2}$ The translation is mine.

${ }^{3}$ Generic masculine form is used to alleviate the text.

${ }^{4}$ For a complete presentation and analysis of the context and methodology of this research, see Assude \& Gélis 2002 and Gélis \& Assude 2002.

5 "CM" stands for "cours moyen". The pupils are 10 years old; it is the last year of French primary school. Teachers teach the same grade level during several years and their pupils change every year.

${ }^{6}$ The "task box" is a series of activities on quadrilaterals that is not structured according to a period of time.

${ }^{7}$ A construction programme is a list of instructions for building a geometric figure.

${ }^{8}$ The drawing is what one sees, while the figure is the class of drawings having the same geometrical invariants (see for example, Parzysz 1988, Laborde \& Capponi 1994, Laborde 1998, Fischbein 1993).

${ }^{9}$ See an analysis of this type of activity in Jones 2000.

${ }^{10}$ In the Cabri software, the "historical" or "return to construction" command in the most recent versions allows the user to go over the different stages of the construction of a figure by displaying consecutive representations of the figure and naming the objects constructed in succession.
}

\section{REFERENCES}

Artigue, M.: 1998, 'Rapports entre la dimension technique et conceptuelle dans l'activité mathématique avec des systèmes de mathématiques symboliques', Actes de l'Université d'été 1996 “ Des outils informatiques dans la classe... ”, IREM de Rennes, pp.19-40.

Artigue M.: 2001, 'Learning mathematics in a CAS environment: the genesis of a reflection about instrumentation and the dialectics between technical and conceptual work', Journal of Computers for Mathematical Learning, 7(3), 245-274.

Artigue M. and Lagrange J.-B.: 1999, 'Instrumentation et écologie didactique de calculatrices complexes: éléments d'analyse à partir d'une expérimentation en classe de Première S', in D. Guin (ed) Actes du congrès "Calculatrices symboliques et géométriques dans l'enseignement des mathématiques ", IREM de Montpellier, pp. 15-38.

Arzarello F., Bartolini-Bussi M.G. \& Robutti O.: 2002, 'Time(s) in Didactics of Mathematics. A Methodological Challenge', in L. English and alii (eds), Handbook of International Research in Mathematics Education, Lawrence Erlbaum Associates Publishers, Mahwah, pp.525-552.

Assude T. and Gélis J.M.: 2002, 'Dialectique ancien-nouveau dans l'intégration de Cabri-géomètre à l'école primaire', Educational Studies in Mathematics, 50, 259-287.

Assude T. and Paquelier Y.: 2004, 'Acte de souvenir et approche temporelle des apprentissages mathématiques', Revue Canadienne de l'Enseignement des Sciences, des Mathématiques et des Technologies (to appear). 
Bosch M. and Chevallard Y.: 1999, 'La sensibilité de l'activité mathématique aux ostensifs. Objet d'étude et problématique', Recherches en didactique des mathématiques, 19.1,77-124.

Brousseau G.: 1997, Theory of Didactical Situations in Mathematics, translated and edited by N. Balacheff, M. Cooper, R. Sutherland, V. Warfield, Kluwer Academic Publishers, Dordrecht.

Brousseau G.: 1998, Théorie des situations didactiques, La Pensée Sauvage, Grenoble.

Brousseau G. and Centeno J.: 1991, 'Rôle de la mémoire didactique de l'enseignant', Recherches en Didactique des Mathématiques, 11-2/3, 167-210.

Chevallard Y.: 1985, La transposition didactique. Du savoir savant au savoir enseigné, La Pensée Sauvage, Grenoble.

Chevallard Y.: 1997, 'Familière et problématique, la figure du professeur', Recherches en didactique des mathématiques, 17.3, 17-54.

Chevallard Y.: 1999, 'L'analyse des pratiques enseignantes en théorie anthropologique du didactique', Recherches en didactique des mathématiques, 19.2, 221-266.

Chevallard Y. and Mercier A.: 1987, Sur la formation historique du temps didactique, Publication de l'IREM d'Aix-Marseille, ${ }^{\circ} 8$, Marseille.

Fischbein E.: 1993, 'The theory of figural concepts', Educational Studies in Mathematics, 24.2, 139162.

Gélis J.-M. and Assude T.: 2002, 'Indicateurs et modes d'intégration du logiciel Cabri en CM2', Sciences et Techniques Educatives, 9-3.4, 457-490.

Jones K.: 2000, 'Providing a foundation for deductive reasoning : students' interpretations when using dynamic geometry software and their evolving mathematical explanations', Educational Studies in Mathematics, 44 (1-3), 55-85.

Laborde C., Capponi B.: 1994, 'Cabri-géomètre constituant d'un milieu pour l'apprentissage de la notion de figure géométrique', Recherches en Didactique des Mathématiques, 14-1.2, 165-210.

Laborde C.: 1998, 'Visual phenomena in the teaching/learning of geometry in a computer-based environment', in C. Mammana and V. Villani (eds), Perspectives on the teaching of geometry for the $21^{\text {st }}$ century, Kluwer Academic Publishers, Dordrecht, pp.113-121..

Lagrange J.-B.: 2001, 'L'intégration d'instruments informatiques dans l'enseignement : une approche par les techniques', Educational Studies in Mathematics, 43, 1-30.

Lagrange J.-B., Artigue M., Laborde C. and Trouche L.: 2001, 'A Meta Study on IC Technologies in Education', PME 25, 1, 111-125.

Lagrange J.-B., Artigue M., Laborde C. and Trouche L.: 2003, 'Technology and Mathematics Education: A Multidimensional Study of the Evolution of Research and Innovation', in A. Bishop and alii (eds), Second International Handbook of Research in Mathematics Education, Kluwer Academic Publishers, Dordrecht, pp.239-271.

Lemke J.L.: 2000, 'Across the Scales of Time : Artifacts, Activities, and Meanings in Ecosocial Systems', Mind Culture and Activity, 7, 273-290.

Leutenegger F.: 2000, 'Construction d'une "clinique" pour le didactique. Une etude des phénomènes temporels de l'enseignement', Recherches en Didactique des Mathématiques, 20.2, 209-250.

Matheron Y.: 2001, 'Une modélisation pour l'étude de la mémoire', Recherches en Didactique des Mathématiques, 21.3, 207-246.

Mercier A.: 1995, 'La biographie didactique d'un élève et les contraintes de l'enseignement', Recherches en didactique des mathématiques, 15.1, 97-142.

Parzysz B.: 1988, 'Knowing vs seeing, Problems of the plane representation of space geometry figures', Educational Studies in Mathematics, 19.1, 79-92.

Pronovost G.: 1996, Sociologie du temps, De Boeck Université, Bruxelles.

Rabardel P.: 1999, 'Eléments pour une approche instrumentale en didactique des mathématiques', Actes de la Xème Ecole d'Eté de Didactique des Mathématiques, Houlgate, vol I, pp.203-213.

Sensevy G.: 1996, 'Le temps didactique et la durée de l'élève. Etude d'un cas au cours moyen : le journal des fractions', Recherches en didactique des mathématiques, 16.1, 7-46.

Varela, F.J.: 1999, 'The Specious Present: A Neurophenomenology of Time Consciousness', in J. Petitot (ed), Naturalizing Phenomenology, Stanford University Press, Stanford, pp.266-314. 


\section{TERESA ASSUDE}

UMR « Apprentissage, Didactiques, Evaluation, Formation »

IUFM d'Aix-Marseille, Université de Provence, INRP

2 av Jules Isaac

13626 Aix-en-Provence cedex 1

France 